\title{
Rancang Bangun Otomasi Oxygen Flow Meter Berbasis Level Spo2 (Parameter Spo2)
}

\author{
Alcham Andrian \#, M. Ridha Mak'ruf, Moch. Prastawa Assalim Tetra Putra \\ Departemen Electromedical Teknik Poltekkes Kemenkes, Surabaya \\ Jl. Pucang Jajar Timur No. 10, Surabaya, 60245, Indonesia \\ \#andrian.alcham@gmail.com, m.reedha@gmail.com, mpatp77@yahoo.com
}

\begin{tabular}{l}
\multicolumn{1}{c}{ Info Artikel } \\
\hline Penerimaan Artikel: \\
Diterima 9 Maret 2019 \\
Revisi 15 Des 2020 \\
Terbit 18 Des 2020 \\
\hline
\end{tabular}

\section{Kata kunci:}

Oxygen

Oxygen Theraphy

Pulse Oximetry

Finger Sensor

\begin{abstract}
Abstrak
Oxygen theraphy adalah suatu tindakan medis yang bertujuan agar kadar oksigen di dalam tubuh tercukupi. Pada level tertentu, jika tubuh kekurangan atau kelebihan oksigen dalam darah dan tidak segera ditangani, akan dapat membahayakan kondisi pasien. Dalam pemberian oxygen theraphy, harus sesuai dengan dosis yang seharusnya dengan memantau secara terus menerus tingkat saturasi oxygen pasien. Tujuan dari penelitian ini adalah merancang alat yang dapat memantau keadaan saturasi oksigen dalam darah pasien. Kontribusi penelitian ini adalah sebagai acuan untuk pemberian oxygen theraphy (oksigenisasi) pada pasien. Agar alat ini lebih praktis dan efisien untuk digunakan, maka dibuatnya alat dengan pemantauan secara real time. Perancangan alat ini menggunakan menggunakan finger sensor DS-100A untuk mengambil pancaran cahaya yang diserap oleh hemoglobin untuk kemudian diolah dan dihasilkan nilai $\mathrm{SpO}_{2}$. Hasil dari modul berupa nilai pembacaan $\mathrm{SpO}_{2}$ dalam persentase. Dari hasil pengujian yang dilakukan dengan alat ukur standar pada responden dihasilkan persentase error paling besar $1,7 \%$. Hasil penelitian ini dapat diimplementasikan pada regulator oksigen otomatis berdasarkan tingkat $\mathrm{SpO}_{2}$ pasien untuk meningkatkan efisiensi sistem pemantauan tingkat $\mathrm{SpO}_{2}$ pasien dalam pemberian dosis pada metode oxygen theraphy (oksigenisasi).
\end{abstract}

\section{Abstract}

Oxygen therapy is a medical procedure that aims to make the oxygen levels in the body sufficient. At a certain level, if the body lacks or excess oxygen in the blood and is not treated immediately, it can endanger the patient's condition. In administering oxygen therapy, it must be in accordance with the appropriate dose by continuously monitoring the level of oxygen saturation of the patient. The purpose of this study is to design a device that can monitor the state of oxygen saturation in a patient's blood. The contribution of this study is as a reference for administering oxygen therapy (oxygenation) to patients. In order to make this tool more practical and efficient to use, it is made with monitoring tools in real time. The design of this tool uses a DS-100A finger sensor to take the beam of light absorbed by hemoglobin to then be processed and the resulting $\mathrm{SpO} 2$ value. The result of the module is the $\mathrm{SpO} 2$ reading value as a percentage. From the results of tests conducted with standard measuring tools on the respondents produced the largest percentage of errors of $1.7 \%$. The results of this study can be implemented on an automatic oxygen regulator based on the patient's SpO2 level to improve the efficiency of the patient's SpO2 level monitoring system in dosing the oxygen theraphy method.
This work is an open access article and licensed under a Creative Commons Attribution-ShareAlike 4.0 International License (CC BY-SA 4.0).

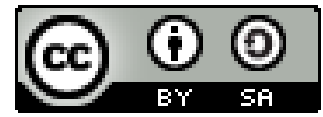

\section{Pendahuluan}

Oksigen $\left(\mathrm{O}_{2}\right)$ merupakan komponen gas yang sangat berperan dalam proses metabolisme tubuh. Ketika tubuh dalam kondisi mempunyai penyakit tertentu, maka akan menimbulkan penyakit dan gangguan sistem kerja tubuh yang lain [1][2][3]. Oxygen theraphy akan memberikan oksigen ekstra bagi tubuh untuk bekerja dengan baik. Pada suatu oxygen theraphy akan dibutuhkan acuan dalam pemberian dosis oksigen sesuai dengan kondisi saturasi oksigen pada pasien [4]. Maka dari itu keberadaan alat monitoring sangat diperlukan untuk membantu tenaga medis untuk mengetahui kadar oksigen pasien, sehingga setiap perubahan terhadap kondisi pasien dapat selalu terpantau [5][6][7]. Salah satu alat monitoring keadaan pasien yang vital adalah pulse oximetry.

Pada penelitian sebelumnya mengenai alat ukur saturasi oksigen dengan metode non-invasive pernah dibuat oleh Teguh Pratomo pada tahun 2016 dengan judul "Finger Pulse Oxymeter Tampil PC". Alat tersebut masih belum portable, kemudian hasil dari pengolahan data berupa grafik sinyal dan persentase $\mathrm{SpO}_{2}$ ditampilkan pada $\mathrm{PC}$, sehingga alat menjadi kurang praktis [8]. Kemudian pada tahun 2012 dikembangkan oleh Soroor Behbahani dkk dari Departemen Teknik 
Biomedis, Universitas Islam Azad yang diberi judul "New Oxygenation Method Based on Pulse Oximeter". Alat ini dibuat dengan tujuan melakukan pemantauan oksigenasi terus menerus agar perubahan tingkat oksigen tidak terdeteksi sampai terlambat [9]. Alat ini sudah menggunakan fingertip model transmittan, dimana tingkat kesalahannya lebih kecil daripada model reflectan [10]. Kekurangan dari alat ini adalah program menggunakan sistem tipe microcontroller 8051. Maka dari itu penulis akan mengaplikasikan sistem ini pada pemrograman Arduino.

Berdasarkan hasil telusur pustaka dan identifikasi masalah dari beberapa artikel jurnal penelitian ditemukan bahwa alat pulse oximeter dapat dikembangkan sebagai acuan metode baru dalam hal oksigenisasi (oxygen theraphy). Dari jurnal sebelumnya juga ditemukan bahwa alat pulse oximeter dengan fisik yang kurang portable. Untuk menyempurnakan beberapa kelemahan yang ada dari penelitian sebelumnya, penulis berencana membuat penelitian yang berguna untuk memeriksa kadar oksigen dalam darah untuk digunakan pada proses oksigenisasi secara portable. Alat berupa modul pulse oximetry dengan display LCD karakter 16 x 4 yang akan menampilkan persentase nilai saturasi oksigen dalam darah dari pasien serta dapat digunakan sebagai acuan dosis pengontrolan oxygen flow meter (regulator oksigen) pada oxygen theraphy secara otomatis[6], [11].

Artikel ini terdiri dari 5 bagian, Bagian I berisi pendahuluan yang menjelaskan tentang latar belakang masalah, tujuan dan manfaat penelitian. Bagian II berisi bahan dan metode yang menjelaskan tentang alat-alat, bahan dan metode yang digunakan dalam penelitian. Bagian III merupakan hasil-hasil yang didapatkan pada penelitian ini. Bagian IV adalah pembahasan temuan-temuan dari penelitian ini dan Bagian $\mathrm{V}$ adalah kesimpulan.

\section{BAHAN DAN Metode}

\section{A. Rancangan Penelitian}

Penelitian ini menggunakan responden orang dewasa dengan usia 19-23 tahun. Pengambilan data dilakukan secara acak dengan membandingkan hasil pengukuran menggunakan alat standar finger pulse oximeter. Pengambilan data dilakukan sebanyak 3 kali.

\section{1) Alat dan Bahan}

Penelitian menggunakan finger sensor DS-100A yang ditunjukkan pada Gambar 1. (Vinmax, Finger Sensor, China) yang berfungsi untuk mendeteksi pancaran cahaya yang diserap oleh hemoglobin melalui jari telunjuk pada orang dewasa. Komponen yang digunakan yaitu mikrokontroller Arduino Nano, Op-amp sebagai penguat dan filter untuk memproses hasil nilai $\mathrm{SpO}_{2}$, LCD karakter 16 x 4 sebagai tampilan. Pada penelitian ini menggunakan alat standar pembanding Finger Pulse Oximeter (General Care, SONOSAT-F04T) dengan resolusi $1 \%$. [12].

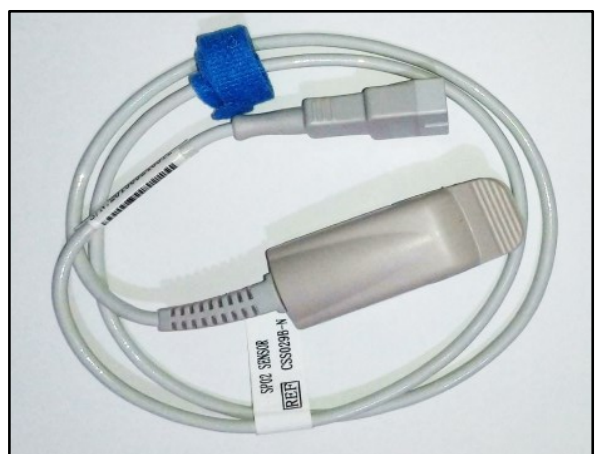

Gambar 1. Finger sensor DS-100A

\section{2) Metodologi}

Pada penelitian ini melakukan pengukuran output dari rangkaian dengan menggunakan serial plotter arduino untuk mengetahui sinyal. Peneliti juga menggunakan finger pulse oximeter untuk membandingkan nilai hasil pengukuran menggunakan modul.

\section{B. Blok Diagram Sistem $\mathrm{SpO}_{2}$}

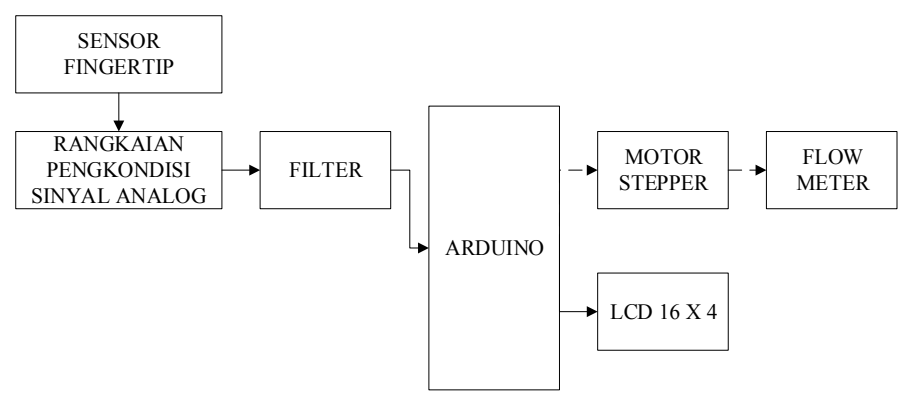

Gambar 2. Blok Diagram Sistem $\mathrm{SpO}_{2}$

Pada Gambar 2. yang diberi garis lurus adalah parameter yang penulis buat, yaitu parameter $\mathrm{SpO}_{2}$. Finger sensor akan mendeteksi kadar oksigen dalam darah pada jari tangan dan kemudian diproses oleh pengkondisian sinyal analog. Kemudian masuk pada rangkaian filter. Sinyal output dari filter akan diubah menjadi data digital oleh ADC dari Mikrokontroller. Kemudian hasil pengolahan nilai $\mathrm{SpO}_{2}$ pasien akan ditampilkan pada LCD karakter 16 x 4.

\section{Diagram Alir / Flowchart}

Berdasarkan flowchart pada yang ditunjukan pada Gambar 3. setelah proses inisialisasi, arduino akan mulai mendeteksi sinyal dari hasil pancaran cahaya merah dan infra merah. Jika deteksi sinyal tidak berhasil makan akan kembali lagi untuk pengulangan proses deteksi sinyal. Data AC dan DC akan dihitung dan dilakukan konversi data yang kemudian akan dihasilkan nilai $\mathrm{SpO}_{2}$. Hasil nilai $\mathrm{SpO}_{2}$ diproses untuk diumpankan ke rangkaian regulator oksigen (flow meter) agar dapat bekerja secara otomatis dan hasil nilai persentase $\mathrm{SpO}_{2}$ ditampilkan melalui LCD karakter 16 x 4. 


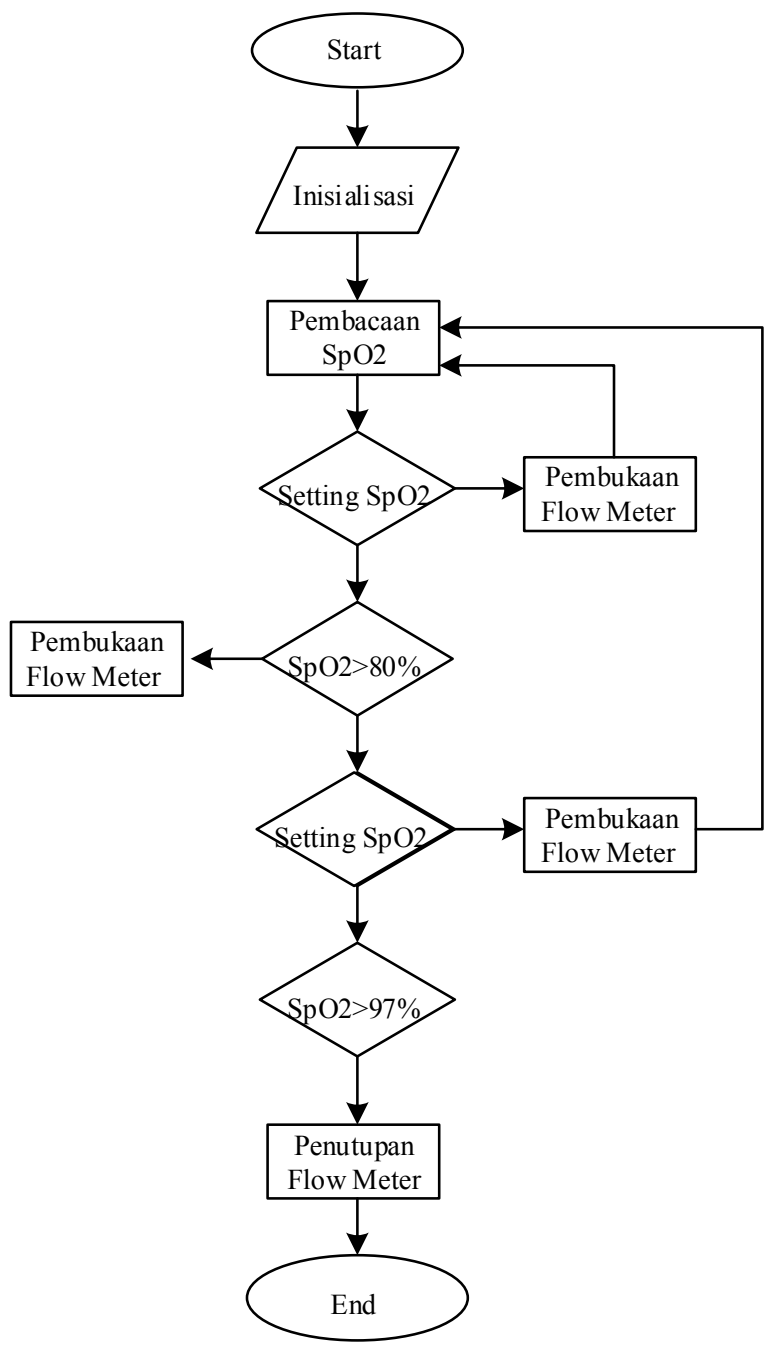

Gambar 3. Diagram Alir Sistem

D. Rangkaian Analog

1) Rangkaian Amplifier dan Filter

Rangkaian amplifier dan filter yang ditunjukkan pada Gambar 4. berfungsi untuk memblok tegangan DC kemudian hanya melewatkan sinyal AC dari output demultiplexer. Pada rangkaian kedua berfungsi untuk menekan ampiltudo pada saat melewati frekuensi cut off agar sinyal noise terlihar lebih tipis.

Hasil yang didapatkan berupa output AC IR dan AC RED. Sinyal AC terbentuk dari sadapan sensor terhadap darah yang mendeteksi pembuluh darah arteri sedangkan sinyal DC terbentuk dari sadapan sensor yang mendeteksi pembuluh dara vena [2], [13], [14].

2) Rangkaian Astable
Rangkaian Astable pada Gambar 5. berfungsi sebagai pembangkit Pulse Width Modulation (PWM) yang diintegrasikan dengan sensor medis yaitu sensor fingertip[15].
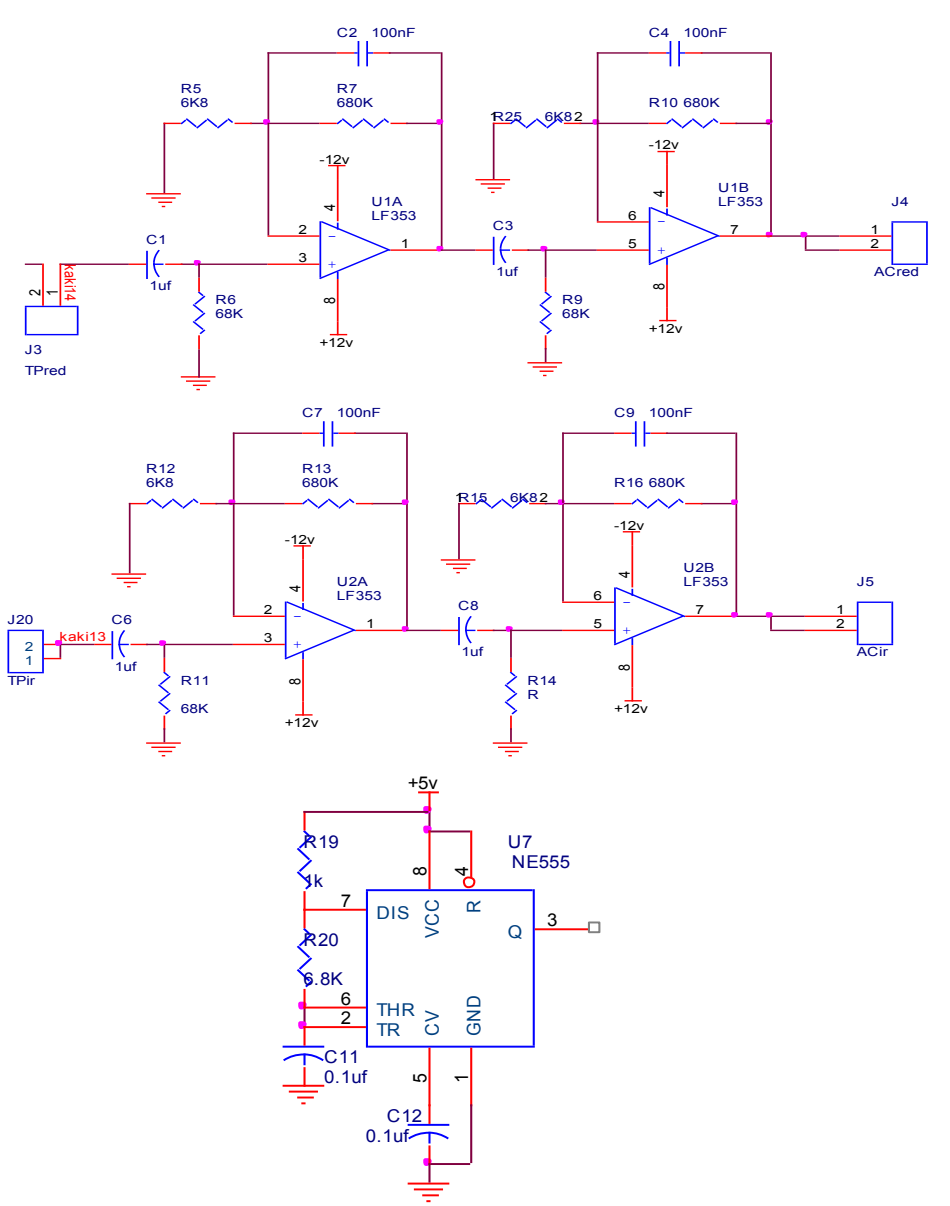

Gambar 4. Rangkaian Astable

Rangkaian astable akan bekerja sesuai frekuensi (Hertz) yang dihasillkan dengan bergantung pada nilai komponen R1, R2 dan C1 [16], [17]. Rangkaian astable akan bekerja mengatur cahaya merah dan inframerah untuk menyala secara bergantian dengan frekuensi sebesar $1000 \mathrm{~Hz}$.

3) Rangkaian Low Pass Filter $0,8 \mathrm{~Hz}$ 
Rangkaian ini berfungsi untuk mengkondisikan output demultiplexer agar menghasilkan sinyal DC dari cahaya merah dan inframerah [18].
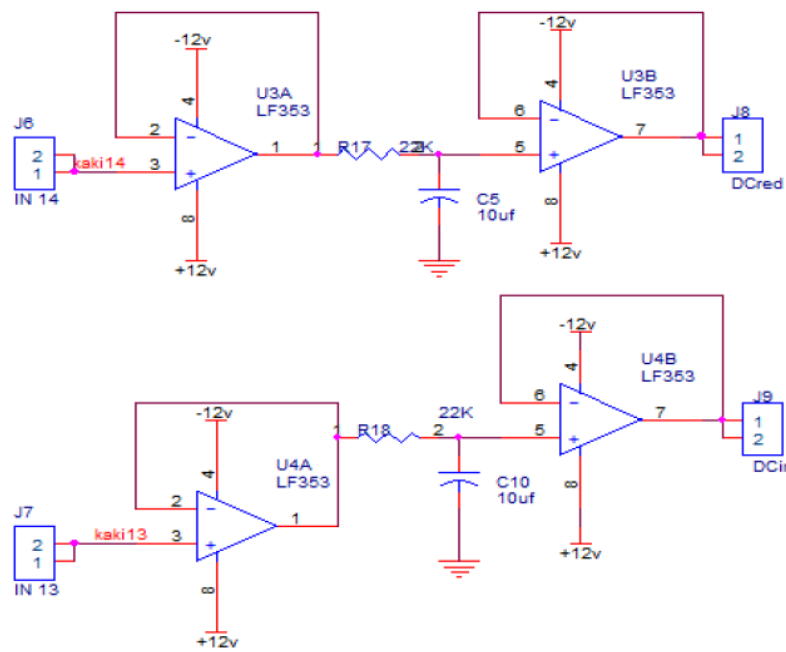

Gambar 5. Rangkaian Low Pass Filter $0,8 \mathrm{~Hz}$

Pada rangkaian ini digunakan rangkaian low pass filter dengan frekuensi cut off sebesar $0,8 \mathrm{~Hz}$ untuk membuang sinyal AC dan melewatkan sinyal DC.

\section{HASIL}

Penelitian ini melakukan tes pada responden yang langsung pada tubuh responden yaitu jari telunjuk orang dewasa untuk penempatan sensor fingertip.

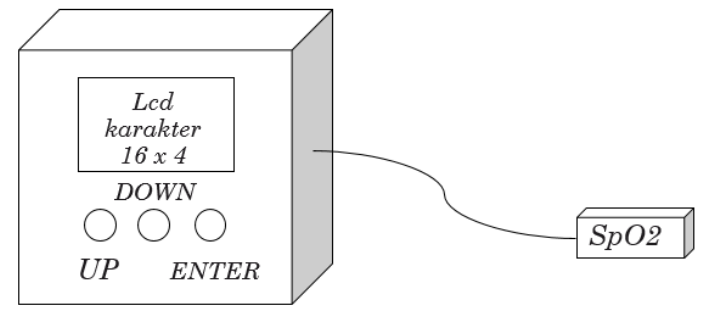

Gambar 6. Desain Alat

\section{1) Desain Alat}

Pada Gambar 7. didesain berupa sebuah modul dengan bentuk fisik kotak yang di dalamnya terdapat rangkaian modul $\mathrm{SpO}_{2}$ dan rangkaian untuk kontrol flow meter otomatis. Untuk penyadapan, alat ini menggunakan sensor fingertip DS-100A yang terdapat konektor di bagian samping box modul. Terdapat push button up, down, dan enter yang berfungsi sebagai input dalam pemberian dosis oksigenisasi.

2) Listing program Arduino

Listing program arduino untuk inisialisasi arduino terdapat pada Program 1, program untuk menghitung nilai $\mathrm{SpO}_{2}$ ditampilkan pada program 2, program untuk menampilkan hasil nilai $\mathrm{SpO}_{2}$ ditujukan pada program 3 .

Listing program 1. Inisialisasi Arduino

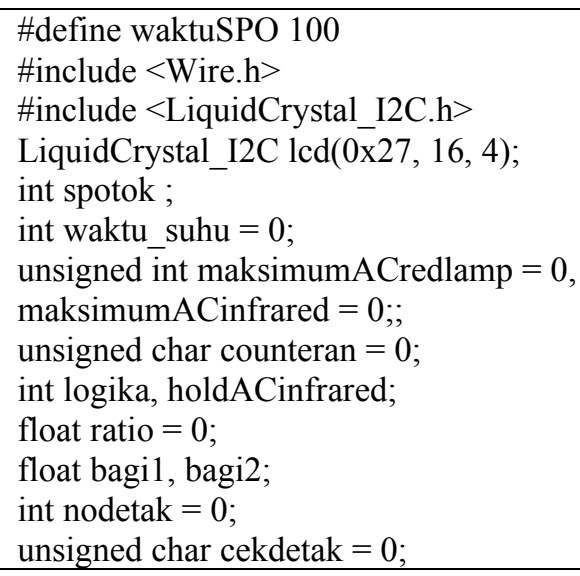

Listing Program 2. Program perhitungan nilai $\mathrm{SpO}_{2}$

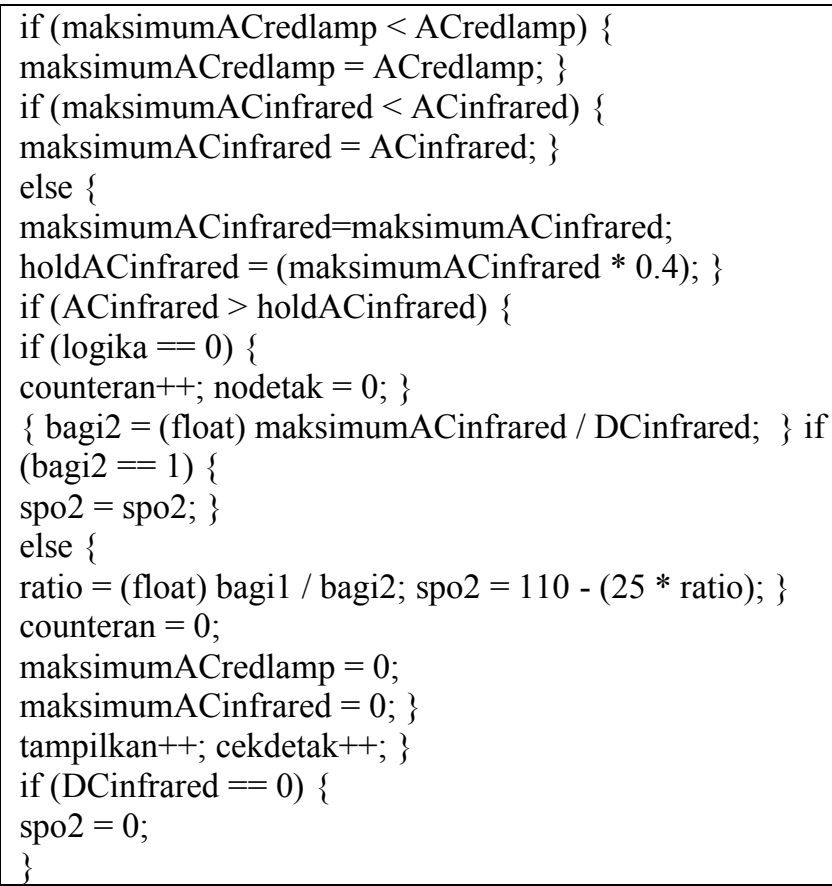

Listing Program 3. Program untuk menampilkan hasil nilai $\mathrm{SpO}_{2}$

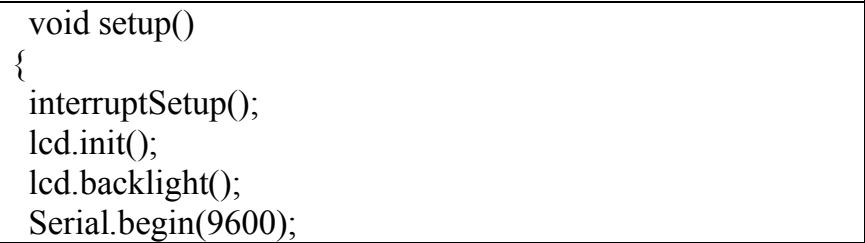




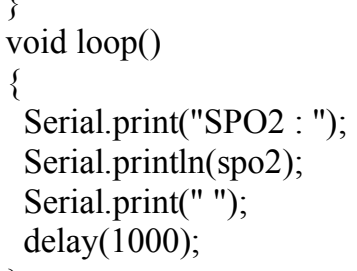

3) Hasil Pengukuran pada Responden

Pengambilan data dilakukan pada 3 responden dengan masing-masing 3 kali pengukuran, didapatkan hasil seperti Tabel 1. di bawah.

Tabel 1. Hasil Pengukuran Modul Terhadap Responden

\begin{tabular}{|l|c|c|}
\hline Responden & Pengukuran & $\begin{array}{c}\text { Nilai } \\
\text { SpO2 }\end{array}$ \\
\hline \multirow{3}{*}{ Responden 1 } & 1 & $95 \%$ \\
\cline { 2 - 3 } & 2 & $97 \%$ \\
\hline \multirow{3}{*}{ Responden 2 } & 3 & $98 \%$ \\
\cline { 2 - 3 } & 2 & $97 \%$ \\
\hline \multirow{3}{*}{ Responden 3 } & 3 & $97 \%$ \\
\cline { 2 - 3 } & 2 & $98 \%$ \\
\cline { 2 - 3 } & 3 & $95 \%$ \\
\hline
\end{tabular}

\section{DISKUSI}

Pulse oximeter salah satu alat monitoring yang diperlukan dalam pemantauan kondisi kadar saturasi oksigen $\left(\mathrm{SpO}_{2}\right)$ pasien [19], [20]. Dengan merancang suatu alat oksigenisasi dilengkapi dengan pemantauan $\mathrm{SpO}_{2}$ yang mampu memantau secara non-kontak, diharapkan alat ini akan berguna bagi tenaga medis. Alat ini juga digunakan sebagai acuan regulator oksigen otomatis berdasarkan tingkat $\mathrm{SpO}_{2}$ pasien untuk meningkatkan efisiensi sistem pemantauan tingkat $\mathrm{SpO}_{2}$ pasien dalam proses oksigenisasi [9].

Pada penelitian sebelumnya mengenai alat ukur saturasi oksigen, alat tersebut masih belum portable, kemudian hasil dari pengolahan data berupa grafik sinyal dan persentase $\mathrm{SpO}_{2}$ ditampilkan pada PC, sehingga alat menjadi kurang praktis [21]. Penelitian yang telah dibuat oleh Andrey Arantra Putra dari jurusan Teknik Elektronika Politeknik Elektronika Negeri Surabaya setelah dibandingkan dengan oximetri standart didapatkan persen error sebesar 1,5\% [22]. Alat yang telah dikembangkan oleh Soroor Behbahani menggunakan pemrograman The89s51 (microcontroller 8051) dan tidak dapat diketahui tentang nilai komponen, perhitungan nilai frekuensi, cut off, dsb., sehingga hal ini tidak dapat diketahui secara pasti pada hasil masing-masing output AC dan DC [9].

Dalam pemantauan kadar saturasi oksigen menggunakan sensor fingertip Nellcor DS-100A untuk mendeteksi pancaran cahaya yang diserap oleh hemoglobin melalui jari telunjuk pada orang dewasa. Modul ini dapat terintegrasi dengan modul rangkaian regulator oksigen otomatis dan tampilan presentase hasil $\mathrm{SpO}_{2}$ pada LCD karakter yang tidak terpisah, sehingga modul lebih compact.

Pada perancangan alat ini terdapat beberapa kelemahan. Fingertip sensor jika digunakan pada tempat yang cahaya terang akan mempengaruhi hasil nilai pembacaan bisa juga $\mathrm{SpO}_{2}$ tidak terdeteksi. Pada saat percobaan, modul $\mathrm{SpO}_{2}$ ini mendapatkan hasil nilai acak dikalibrasikan dengan simulator $\mathrm{SpO}_{2}$ tertentu.

\section{KESIMPULAN}

Tujuan dari penelitian ini adalah untuk merancang suatu metode oksigenisasi yang bekerja secara otomatis dengan memodifikasi alat oxygen flow meter agar dapat melakukan pemberian dosis oksigenisasi sesuai dengan yang dibutuhkan oleh pasien dengan menggunakan acuan tingkat kadar oksigen pada pasien. Penelitian ini diharapkan bahwa dengan menggunakan pulse oximeter untuk memantau perkembangan saturasi oksigen pasien, maka akan mempermudah tenaga medis mengetahui kekurangan oksigen tepat waktu, sehingga tidak harus setiap saat mengawasi pasien dalam pengaturan kompensasi dosis oksigenisasi. Dengan menggunakan acuan nilai hasil presentase $\mathrm{SpO}_{2}$, kemudian diolah kembali untuk pengontrolan regulator oksigen otomatis dengan terhubung pada modul rangkaian oxygen flow meter untuk melakukan proses oksigenisasi sesuai tingkat $\mathrm{SpO}_{2}$. Pada hasil penelitian ini menunjukkan keakurasian modul pada pengukuran nilai saturasi oksigen normal yang dapat dikategorikan cukup. Dari hasil pengukuran dengan pembanding, modul $\mathrm{SpO}_{2}$ ini memiliki error terkecil $0,3 \%$ dan terbesar $1,7 \%$. Tingkat error pada hasil nilai $\mathrm{SpO}_{2}$ tersebut disebabkan oleh pergerakan dari pasien dan pasien yang kurang rileks. Alat ini dapat berfungsi dengan baik dalam memantau kondisi kadar saturasi oksigen pada pasien. Dengan ukuran yang compact dimana antara display dan modul tidak terpisah. Penelitian ini dapat disempurnakan lagi oleh peneliti selanjutnya dengan menambahkan mode wireless agar dapat dipantau secara real time dan alarm peringatan ketika nilai $\mathrm{SpO}_{2}$ tidak normal.

\section{Daftar Pustaka}

[1] A. Chawla dan A. K. Lavania, "Oxygen toxicity," Med. J. Armed Forces India, vol. 57, no. 2, hal. 131-133, 2001.

[2] "A Real Time Analysis of PPG Signal for Measurement of SpO2 and Pulse Rate," Int. J. Comput. Appl., 2011.

[3] M. Sarkar, N. Niranjan, dan P. K. Banyal, "Mechanisms of hypoxemia," Lung India, vol. 34, no. 1, hal. 47-60, 2017.

[4] R. Langley dan S. Cunningham, "How Should Oxygen Supplementation Be Guided by Pulse Oximetry in Children: Do We Know the Level?," Front. Pediatr., vol. 4, no. January, 2017. 
[5] P. Pulse et al., "EM.S.Tr.19.031,” 2019.

[6] B. R. O’Driscoll, L. S. Howard, dan A. G. Davison, "BTS guideline for emergency oxygen use in adult patients," Thorax, vol. 63, no. SUPPL. 6, 2008.

[7] S. Khairunnisa, I. D. Gede, H. Wisana, I. Priyambada, C. Nugraha, dan J. T. Elektromedik, "Rancang Bangun Pulse Oximeter Berbasis Iot ( Internet of Things )," 2014.

[8] P. Galuh, A. Pradana, H. E. D. S, M. R. Ma, M. Si, dan J. T. Elektromedik, "Tampil Led Grafik," hal. 1-7, 2001.

[9] S. Behbahani dan M. Ali Pishbin, "New Oxygenation Method Based on Pulse Oximeter," Am. J. Biomed. Eng., vol. 2, no. 4, hal. 185-188, 2012.

[10] D. B. Wax, P. Rubin, dan S. Neustein, "A comparison of transmittance and reflectance pulse oximetry during vascular surgery," Anesth. Analg., vol. 109, no. 6, hal. 1847-1849, 2009.

[11] F. UGHI, "Proof-of-Concept Simulasi Kadar Saturasi Oksigen untuk Evaluasi Pulse Oximeter," ELKOMIKA J. Tek. Energi Elektr. Tek. Telekomun. Tek. Elektron., vol. 6, no. 1, hal. 110, 2018.

[12] U. Manual, "Arduino Nano V2.3 User Manual," Arduino, hal. 1-5, 2008.

[13] P. Madhan Mohan, A. Annie Nisha, V. Nagarajan, dan E. Smiley Jeya Jothi, "Measurement of arterial oxygen saturation (SpO2) using PPG optical sensor," in International Conference on Communication and Signal Processing, ICCSP 2016, 2016.

[14] J. Lee, W. Jung, I. T. Kang, Y. Kim, dan G. Lee, "Design of filter to reject motion artifact of pulse oximetry," Comput. Stand. Interfaces, 2004.

[15] A. S. Salgia, K. Ganesan, dan A. Raghunath, "Smart pill box," Indian J. Sci. Technol., 2015.

[16] M. M. Abrar, "Design and Implementation of Astable Multivibrator using 555 Timer," IOSR J. Electr. Electron. Eng., 2017.

[17] D. S. Yu, C. Y. Zheng, H. H. C. Iu, dan T. Fernando, "A memristive astable multivibrator based on 555 timer," in Proceedings - IEEE International Symposium on Circuits and Systems, 2015.

[18] N. Stuban dan M. Niwayama, "Optimal filter bandwidth for pulse oximetry," in Review of Scientific Instruments, 2012.

[19] S. Lopez, "Pulse Oximeter Fundamentals and Design," Free. Semicond. Inc., hal. 1-39, 2012.

[20] E. Jahan, T. Barua, dan U. Salma, "an Overview on Heart Rate Monitoring," Int. J. latest Res. Sci. Technol., vol. 3, no. 5, hal. 148-152, 2014.

[21] E. Kartini et al., "Fingerstip Pulse Oxymeter Tampil PC
( BPM ) sensitif untuk mengetahui kadar oksigen dalam darah ( SPO2 ) dan dari akibat perbedaan kepekatan," Jur. Tek. Elektromedik, Poltekkes Surabaya, hal. 1-8, 2015.

[22] M. . Kemalasari, Ir., "Rancangan Bangunan Pulse Oximetry Digital," 2010. 